\title{
A GESTÃO DE DESIGN NA CONCEPÇÃO DE NOVOS PRODUTOS: UMA FERRAMENTA DE INTEGRAÇ̃̃O DO PROCESSO DE GESTÃO E INOVAÇÃO
}

\author{
MANAGEMENT OF DESIGN IN CONCEPTION OF NEW \\ PRODUCTS: A TOOL FOR INTEGRATION OF CASE \\ MANAGEMENT AND INNOVATION
}

Recebido em 30.08.10 / Aceito em 13.12.10

\section{Ana Claudia Machado Padilha, ${ }^{1}$ Filipe Freitas de Carvalho, ${ }^{2}$ Paloma de Mattos ${ }^{3}$ e Silvana Saionara Gollo ${ }^{4}$}

\section{Resumo}

O artigo tem como objetivo o desenvolvimento de um framework de gestão de design focado na maximização do fluxo de informações no desenvolvimento de produtos inovadores em organizações competitivas. A metodologia utilizada no estudo baseou-se na teoria levantada por meio de revisão bibliográfica, delineando uma pesquisa qualitativa, de caráter exploratório, através de estudo de caso. As variáveis trabalhadas permitiram a análise, identificação e classificação do processo de desenvolvimento de produtos em quatro empresas de diferentes ramos de atividade industrial. O trabalho partiu do pressuposto de que o design, incorporado na estrutura organizacional de uma empresa por meio da gestão de design e integrado com as demais unidades de negócios, fortalece a estratégia das organizações.

Palavras-chave: Design. Produto. Framework.

\footnotetext{
1 Mestre e Doutora em Agronegócios (CEPAN-UFRGS). Professora do Curso de Administração da Universidade de Passo Fundo (UPF) e Pesquisadora dos Grupos Estratégia e Competitividade (UPF) e Gestor (EA-UFRGS). E-mail: anapadilha@upf.br

2 Especialista Gestão de Marketing em Serviços e Varejo (UPF). Coordenador área de Desing da empresa Kuhn Metasa S/A. E-mail: filipefdc@hotmail.com

3 Mestre e Doutoranda em Agronegócios (CEPAN-UFRGS. Professora do Curso de Administração da Universidade Potiguar (UNP). E-mail: palomattos@hotmail.com

4 Doutora em Administração (PPGA-UFRGS). Professora do Curso de Administração da Universidade de Passo Fundo (UPF). E-mail: ssgollo@upf.br
} 


\begin{abstract}
The article aims at developing a framework for the management of design focused on maximizing the flow of information in the development of innovative products at competitive organizations. The methodology used in the study was based on the theory raised by means of literature review, outlining a qualitative research, exploratory in nature, through case study. The variables worked led the analysis, identification and classification of the process of developing products in four companies of different branches of industrial activity. The work started from the assumption that the design, incorporated in the organizational structure of a company through the management of design and integrated with other business units, strengthens the strategy of organizations.
\end{abstract}

Keywords: Design. Product. Framework.

\title{
1 INTRODUÇÃO
}

A abertura econômica mundial, juntamente aos processos de internacionalização de empresas, vem exigindo esforços crescentes de capacitação tecnológica e intensificação das atividades de P\&D. Assim, cada vez mais a sobrevivência e crescimento das empresas dependem das capacidades individuais de criar e sustentar vantagens competitivas.

Nesse cenário, surge o design que, no entendimento de Stoner e Freeman (1985), é uma atividade crucial no processo de inovação, onde as ideias são geradas no domínio da criatividade e acopladas entre possibilidades técnicas, demandas e oportunidades de mercado. Além disto, é uma atividade articuladora e multidisciplinar que integra planos estratégicos e operacionais de acordo com a visão e missão da empresa, desenvolvendo produtos de acordo com as tendências, prazos e custos.

Muitas empresas, erroneamente, acreditam que o design só pode ser utilizado por grandes empresas, em razão do glamour que existe em torno da atividade ou porque pensam que investir em seu desenvolvimento implica em altos custos financeiros. Porém, atualmente, os impactos revolucionários que as organizações vêm enfrentando conduzem-nas a buscarem meIhores resultados nos mercados em que atuam, obrigando-as a pensarem estrategicamente e a reavaliarem seu modelo de gestão.

Uma das razões pela qual a alta administração das organizações tem dado pouca importância ao design, segundo Mozota (1998), é a falta de compreensão da extensão que ele abrange. Frequentemente, tem-se observado, entre os próprios profissionais da área, a dificuldade de transmitir um conceito que traduza a complexidade da atividade. No entanto, design não é apenas o aspecto formal e estético dos produtos. Se o fosse, os gestores teriam a ideia de que um "bom design" seria somente a forma externa, esquecendo sua contribuição para a produção dos produtos (incluindo produtos gráficos), custos unitários, manutenção, valor agregado e qualidade global reconhecida por consumidores e usuários.

Considerando atores como Wolf (1998), Trueman (1998), Coutinho e Ferraz (1995), Kistmann (2002), cabe mencionar que o design deve fazer parte da missão da empresa, sendo sua premissa básica a eficiência, a consciência e a sua utilização pelos tomadores de decisão na organização. No entanto, o design deve ser visto como um processo, e não como um produto; um recurso que contribua para o aumento da eficiência e competitividade organizacional, diferenciação dos produtos (atuando na gestão de processos de mudanças comportamentais), otimização da performance, inovação, qualidade, durabilidade, aparência, custos, informação, marca, entre outros.

Rev. Adm. UFSM, Santa Maria, v. 3, n. 3, p. 346-360, set./dez. 2010 
O que se pode perceber é que a gestão de design aparece, muitas vezes, como parte das políticas organizacionais, apesar de que os modelos atuais, em sua maioria, apontam para a importância de gerenciamento de suas atividades e muito explicam sua operacionalização. Considerando-se a relevância para a competitividade, é importante abordar a forma e os processos de operacionalização do design nas organizações.

Diante desses elementos, este estudo tem como objetivo o desenvolvimento de um framework de gestão de design focado na maximização do fluxo de informações no desenvolvimento de produtos inovadores em organizações competitivas.

Nesse sentido, para o alcance do objetivo proposto, algumas ponderações são elaboradas no sentido de esclarecer de que forma a gestão de design pode ser implantada, gerenciada e, consequentemente, quais benefícios pode proporcionar.

\section{REVISÃO DA LITERATURA}

Esta seção apresenta os principais conceitos discutidos pelos autores selecionados para o estudo proposto.

\subsection{Marketing: a gestão do produto e o sistema de informação}

A utilização do conhecimento oferece à empresa benefícios, tais como o pensamento sistemático, a melhoria de coordenação de esforços, a melhor definição de objetivos e, consequentemente, melhor avaliação do desempenho.

O pensamento de marketing tem sua origem na satisfação de necessidades e nos desejos das pessoas. Segundo Kotler (1996), a necessidade humana é um estado de privação de alguma satisfação básica. O marketing assume que a chave para atingir as metas organizacionais consiste em identificar as necessidades e os desejos do mercado-alvo e satisfazê-las mais eficazmente do que os concorrentes.

Com relação à estratégia de marketing, esta, por sua vez, permite definir como uma empresa atingirá seus objetivos e metas e gerenciará seus relacionamentos com o mercado, também com o intuito de obter vantagens sobre a concorrência.

A importância dos produtos físicos não está apenas em sua posse, mas também nos serviços oferecidos por eles. Frequentemente os fabricantes incorrem no erro de prestar mais atenção aos produtos físicos em detrimento dos serviços fornecidos. No entanto, o objetivo do marketing também é o de transmitir os benefícios ou serviços contidos em produtos físicos, em vez de apenas descrever suas características.

Com relação ao sistema de informação em marketing, Ferrel (2000) menciona que a necessidade de informações de mercado em tempo real é maior do que em qualquer outra época, ou seja, o marketing muda de uma visão local para nacional e, por sua vez, de nacional para global; de necessidades do comprador, para os desejos do comprador; e, de competição de preços, para competição de valor.

Segundo Kotler e Armstrong (1999), algumas empresas desenvolveram sistemas de informações de marketing que suprem a gerência da empresa com informações rápidas e detalhadas sobre desejos, preferências e comportamentos dos compradores. Em muitas empresas não se observa, na estrutura formal, o departamento de pesquisa de marketing. Outras têm departamentos cujo trabalho se limita às projeções rotineiras, análise de vendas e estudos ocasionais. Além disto, muitos gerentes reclamam por não saber onde estão as informações essenciais den- 
tro da empresa, por obter muito mais informações do que eles podem usar e, muito menos do que eles realmente precisariam; por obter as informações importantes quando é tarde e, acima de tudo, por terem em mãos informações imprecisas e duvidosas.

Na sociedade atual, baseada na informação, empresas com melhores sistemas de informações obtêm uma vantagem competitiva. A empresa pode escolher melhor seu mercado, disponibilizar melhores ofertas e, assim, executar melhor seu planejamento de marketing. Empresas competitivas estudam as necessidades de informações de seus gerentes e projetam seus sistemas de informações de modo a satisfazer tais necessidades.

Um sistema de informações é constituído de pessoas, equipamentos e procedimentos para a coleta, classificação, análise, avaliação e disseminação de informações para tomada de decisões estratégicas. O papel do sistema de informações é o de avaliar as necessidades de informação de setores estratégicos, obtê-las e distribuí-las entre os interessados.

\subsection{P\&D e o design de produto}

Volatilidade de mercados, aumento da concorrência, rápidas mudanças tecnológicas, diminuição do ciclo de vida dos produtos, maior exigência por parte dos consumidores, entre outros, são elementos da pressão competitiva global que têm forçado as organizações a encontrarem novos caminhos para melhor atender às necessidades dos seus consumidores de forma efetiva e competitiva. O sucesso competitivo, portanto, decorre da capacidade de criar um novo conhecimento e da capacidade de diversificar, lançar produtos novos que atendam às novas expectativas de um mercado consumidor cada vez mais exigente (DRUCKER, 1995).

No entendimento de Semenik e Bamossy (1996), um dos primeiros requisitos para a criação de um programa bem-sucedido de desenvolvimento de produtos é o entendimento de que esta postura estratégica garantirá a perenidade da organização.

Assim, um dos primeiros passos para o início do desenvolvimento de novos produtos é a identificação da necessidade de crescimento e de diversificação da empresa. De acordo com Drucker (1995), existem duas funções importantes em negócios: marketing e inovação; todo o resto são custos. O desenvolvimento de novos produtos é um processo que envolve desde a geração da ideia, tendo como ponto de partida "as necessidades e desejos dos clientes", passando à seleção dentre as apresentadas, perseguindo um conceito para o novo produto que estimule os consumidores potenciais a comprá-lo, selecionando estratégia compatível e analisando o projeto em função das metas de lucro da organização. Após estes passos, a empresa passa às fases de desenvolvimento do produto, teste no mercado e, por fim, à comercialização (KOTLER, 2000).

Nessa discussão, surge a figura do designer, ou do departamento de design. O termo design foi criado na revolução industrial. Na época, com a possibilidade de se fabricar produtos em escala, a primeira ideia foi a de tentar reproduzir a estética conhecida pelos artesãos. O conceito de design também leva em consideração a ergonomia (estudo da adaptação do homem ao trabalho), a proxêmica (estudo da relação entre o indivíduo e seu ambiente), a biônica (estudo dos sistemas vivos ou semelhantes aos vivos, para descobrir processos, técnicas, e novos princípios aplicáveis à tecnologia), a iluminação e as técnicas de fabricação (FASCIONI, 2007).

As etapas que devem ser seguidas no desenvolvimento de produtos incluem a identificação da oportunidade, o projeto conceitual e o próprio design, em que a geração de ideias é o centro do pensamento criativo. Muitas técnicas de criatividade tentam juntar essas ideias. Segundo Baxter (1998), seria interessante que o designer dominasse todas as técnicas, conhecendo os 
pontos fortes e fracos de cada uma, o que poderia contribuir na escolha da técnica que mais se adaptasse a cada tipo de problema.

Conforme Hauser e Griffin (1992), recentes evidências científicas sugerem que times de desenvolvimento de produtos têm sucesso quando seus membros se comunicam, uma vez que a probabilidade de um produto ter sucesso é aumentada se marketing, $\mathrm{P} \& \mathrm{D}$, design e produção dividirem informações sobre necessidades dos consumidores, segmentos, tecnologias, capacidades de produção, estratégias dos concorrentes, estratégias do negócio e preço.

\subsection{Metodologias de projeto de produto}

As metodologias são fundamentais nos processos de inovação, fornecendo diretrizes para o desenvolvimento de novos produtos e estudos de princípios e procedimentos orientados. Existem técnicas que auxiliam no direcionamento do caminho a seguir e as metodologias de desenvolvimento de produto funcionam como ferramentas efetivas na competitividade dos mercados.

A tecnologia minimizou o tempo de desenvolvimento de um produto, mas a pesquisa e a metodologia necessária para conhecer o desejo do consumidor e do tomador de decisão ainda são compiladas, em grande parte, pela intuição do designer, que se utiliza de metodologias, tendências e procedimentos técnicos que buscam reduzir e minimizar os riscos dos investimentos financeiros.

De acordo com Bomfim (1995), o uso de uma metodologia é necessária devido à complexidade crescente das variáveis envolvidas em um projeto, sugerindo um modelo com cinco variáveis que determinam o desenvolvimento do projeto, tais como: o designer, a organização, o consumidor, a sociedade e o produto em si, o qual representa a necessidade do mercado e do consumidor. O mesmo autor menciona, ainda, que os métodos são ferramentas utilizadas no desenvolvimento de um produto e dependem da capacidade técnica e criativa de quem os utiliza.

No entanto, Bittencourt (2001) enfatiza que o projeto de produto começa com o estabelecimento de um problema, cuja expressão mais comum é um conjunto de necessidades das pessoas, podendo também surgir em qualquer fase do ciclo de vida do produto, bem como ser aplicado em melhorias técnicas, demanda de mercado, de segurança ou de efeitos legais.

Löbach (2000) contribui ao afirmar que todo processo de design é tanto um processo criativo como um processo de solução de problemas, concretizado em um projeto industrial que incorpora características que possam satisfazer as necessidades humanas, podendo ser desenvolvido de forma complexa, dependendo da amplitude do problema. O mesmo autor divide sua metodologia em quatro fases distintas, a saber: análise do problema, geração de alternativas, avaliação das alternativas e realização da solução do problema.

Bonsiepe (1984) conclui que a metodologia não tem finalidade em si mesma, é só uma ajuda no processo projetual, fornecendo uma orientação no procedimento do processo e técnicas e métodos que podem ser usados em certas etapas. Desta forma, o autor menciona que o designer é o ator que controla e decide a melhor alternativa a ser investida.

Com base nas descrições dos autores, uma metodologia deve ser estruturada no sentido de incluir um projeto lógico antes de constituir um projeto físico e abordar os requisitos dos usuários do sistema, bem como a de considerar outras variáveis. A metodologia deve ser interativa, ou seja, novas informações devem alimentar continuamente o projeto à medida que se conhecem as necessidades dos usuários, a fim de corrigir desvios e eventuais falhas. O objetivo básico de qualquer metodologia de projeto, associado a um padrão, deve ser o de fornecer os instrumentos necessários para a sua definição, o seu planejamento, o seu acompanhamento e o seu desenvolvimento. A metodologia deve incluir mecanismos que permitam a criação de um protó- 
tipo do projeto em desenvolvimento que facilitem a análise e a correção das falhas que forem detectadas antes de sua efetiva implantação.

A adoção de uma metodologia proporciona várias vantagens ao desenvolvimento de projetos em uma empresa, em especial, a de evitar a necessidade de revisão de um projeto desde as fases iniciais, uniformização dos procedimentos operacionais, promoção do desenvolvimento de ferramentas operacionais e gerenciais e também a redução do tempo e custos de planejamento da execução das diversas atividades envolvidas.

No entanto, complexidade e a presença de entraves ao processo são fatores indicativos de que a utilização de uma metodologia deve ser conduzida por uma equipe devidamente preparada, que será a responsável pelo desenvolvimento do projeto.

\subsection{Gestão de design}

Em meio às dificuldades de proposição de novas soluções industriais, o que se pode notar é que o design é uma das áreas mais influentes em todo ciclo de vida dos produtos. No entanto, segundo Avendaño (2007), novos desafios para a competência do designer têm surgido nestes últimos anos, seja pelos componentes dados pela globalização que exigem a criação de novas estratégias nas empresas para se tornarem mais competitivas, seja pela velocidade com que a informação chega para todos através da internet e outras mídias. O mesmo autor menciona que, neste processo, o designer tem que adequar seu discurso para a complexidade da ação, sendo necessária a preposição de estratégias e políticas que integrem a organização com o seu consumidor.

A gestão de design está formulada como uma modalidade de pensamento, de ação, destinada a recuperar o protagonismo do design no marco da nova tipologia das mutações que se produzem nos fatores sociais, culturais, econômicos e tecnológicos.

Conforme Ferreira (2004), a palavra gestão vem do latim gestione, significando o ato de gerir, administrar. O processo de gestão, segundo D'Ajuz (2007), resume-se no gerenciamento dos recursos da organização para alcançar objetivos estabelecidos, envolvendo planejamento, execução, controle e ações corretivas.

A gestão estratégica e operacional de design tem como principais funções a definição dos objetivos e valores da empresa (missão). Magalhães (1997) conceitua design estratégico como uma forma de atuação direcionada para a gestão de design nas empresas, integrando produtos e imagem à estratégia da organização, utilizando-o como processo catalisador, sintetizador e materializador de conhecimentos e informações em produtos e serviços.

Para Monteiro (2003), implantar um modelo de gestão estratégica requer o compartilhamento de pessoas e o desenvolvimento de um espaço próprio de construção do projeto coletivo da organização. O design operacional, para Magalhães (1997), é um processo de trabalho realizado de "dentro para fora", tanto em estilo de concepção intelectual e simplicidade funcional, como para o que serve à venda e propaganda.

Vista como uma ferramenta integradora das funções operacionais, alcance dos objetivos operacionais e imagem positiva, a gestão de design pode ser descrita como a atividade macro das estratégias que, em grupos interdisciplinares, com poder decisório em que o design é envolvido, moldam o perfil da empresa com base nos produtos desenvolvidos e/ou identidade visual que a representa (SOARES, 2007). A gestão de design, para Wolf (1998), fundamenta-se na organização e na coordenação de todas as suas atividades baseadas nos objetivos definidos da empresa. É um recurso para a empresa aumentar sua eficiência, manter-se competitiva e diferenciar produtos (TRUEMAN, 1998). 


\section{PROCEDIMENTOS METODOLÓGICOS}

O estudo é de natureza exploratória, tendo aspectos de análise quantitativa e qualitativa, caracterizado por uma pesquisa do tipo bibliográfica e documental, ratificada em um estudo multicaso (TRIVIÑOS, 1992; VERGARA, 1997; YIN, 2001).

Com relação aos dados, os secundários foram coletados em documentos das indústrias selecionadas, bibliografia que discute a temática abordada e sites relacionados. Já os dados primários foram coletados através da realização de entrevistas semiestruturadas, com a utilização de roteiro de questões.

Levando-se em conta o caráter do estudo e seu objetivo, foram selecionadas para o estudo, de forma intencional, quatro indústrias com produção de diferentes produtos, a saber: indústria A (refrigeração - linha branca), indústria B (transportes coletivos), indústria C (cerâmica) E, indústria D (máquinas e implementos agrícolas).

Para o alcance do objetivo, foram delimitadas variáveis observadas nas indústrias selecionadas, tais como a estrutura organizacional, a organização do processo de desenvolvimento, a participação do design no desenvolvimento de produtos e os métodos utilizados na concepção de novos produtos.

Com relação aos participantes das entrevistas, o quadro1 especifica o cargo e as principais funções desenvolvidas pelos selecionados.

\begin{tabular}{|c|c|c|c|c|}
\hline Indústria & A & B & C & D \\
\hline $\begin{array}{c}\text { Participante/ } \\
\text { Cargo }\end{array}$ & $\begin{array}{c}\text { Designer } \\
\text { Gráfico }\end{array}$ & Engenheiro Eletricista & $\begin{array}{c}\text { Desenhista } \\
\text { Industrial }\end{array}$ & $\begin{array}{c}\text { Engenheiro } \\
\text { Mecânico }\end{array}$ \\
\hline $\begin{array}{c}\text { Principais } \\
\text { funções }\end{array}$ & $\begin{array}{c}\text { Criaço e } \\
\text { desáfico dos produtos } \\
\text { (layout, rótulos, } \\
\text { embalagens) }\end{array}$ & $\begin{array}{c}\text { Configuração e } \\
\text { desenvolvimento } \\
\text { elétrico dos produtos } \\
\text { (chicotes elétricos, } \\
\text { iluminação) }\end{array}$ & $\begin{array}{c}\text { Criação e } \\
\text { gerenciamento do mix } \\
\text { de produtos nos } \\
\text { mercados. } \\
\text { (fatias de mercado, } \\
\text { público-alvo) }\end{array}$ & $\begin{array}{c}\text { Criação e } \\
\text { desenvolvimento e } \\
\text { configuração dos } \\
\text { produtos } \\
\text { (pesquisa e } \\
\text { desenvolvimento) }\end{array}$ \\
\hline
\end{tabular}

Quadro 1 - Especificidades dos participantes do estudo nas indústrias selecionadas.

Fonte: Dados do estudo (2008).

Quanto à análise dos dados, a técnica adotada foi a interpretativa. Segundo Triviños (1992), esta técnica possibilita a análise dos dados coletados à luz da revisão da literatura selecionada.

\section{ANÁLISE E DISCUSSÃO DOS RESULTADOS}

Para um melhor entendimento das indústrias estudas, inicialmente é apresentada uma breve descrição de suas especificidades, conforme se pode observar no quadro 2. 


\begin{tabular}{|c|c|c|c|}
\hline Indústria A & Indústria B & Indústria C & Indústria D \\
\hline $\begin{array}{c}\text { Fabricante dos produtos } \\
\text { da linha branca: freezers e } \\
\text { refrigeradores }\end{array}$ & $\begin{array}{c}\text { Fabricante e montador de } \\
\text { carrocerias para } \\
\text { transportes coletivos }\end{array}$ & $\begin{array}{c}\text { Fabricante de produtos } \\
\text { cerâmicos de mesa }\end{array}$ & $\begin{array}{c}\text { Fabricante de máquinas e } \\
\text { implementos agrícolas }\end{array}$ \\
\hline $\begin{array}{c}\text { Aproximadamente 14.000 } \\
\text { colaboradores }\end{array}$ & $\begin{array}{c}\text { Aproximadamente } 6.500 \\
\text { colaboradores }\end{array}$ & $\begin{array}{c}\text { Aproximadamente } \\
1.150 \text { colaboradores }\end{array}$ & $\begin{array}{c}\text { Aproximadamente } 2.800 \\
\text { colaboradores }\end{array}$ \\
\hline 6 unidades no Brasil & $\begin{array}{c}5 \text { unidades no Brasil e } \\
7 \text { unidades no exterior }\end{array}$ & 1 unidade no Brasil & $\begin{array}{c}1 \text { unidade no Brasil e } \\
6 \text { unidades no exterior }\end{array}$ \\
\hline $\begin{array}{c}\text { Produção de } \\
150 \text { mil un./ano }\end{array}$ & $\begin{array}{c}\text { Produção de } \\
20 \text { mil un./ano }\end{array}$ & $\begin{array}{c}\text { Produção de } \\
50 \text { milhões un./ano }\end{array}$ & $\begin{array}{c}\text { Produção de } \\
60 \text { mil un./ano }\end{array}$ \\
\hline $\begin{array}{c}\text { Aproximadamente } \\
\mathrm{R} \$ 5 \text { bilhões em }\end{array}$ & $\begin{array}{c}\text { Aproximadamente } \\
\text { faturamento } \$ 2 \text { bilhões em } \\
\text { faturamento }\end{array}$ & $\begin{array}{c}\text { Aproximadamente } \\
\mathrm{R} \$ 65 \text { milhões em } \\
\text { faturamento }\end{array}$ & $\begin{array}{c}\text { Aproximadamente } \\
\text { R\$1.6 bilhões em } \\
\text { faturamento }\end{array}$ \\
\hline Exportação para & Exportação para & Exportação para & Exportação para \\
60 países & 27 países & 200 países \\
\hline
\end{tabular}

Quadro 2 - Descrição das indústrias estudadas

Fonte: Dados do estudo (2008).

Como se pode verificar no quadro 2, as quatro indústrias dedicam-se à produção de bens, com linhas de produtos distintas e consumidores específicos, realizando a comercialização no mercado interno e externo. As indústrias possuem acima de 1.000 colaboradores e faturamento anual superior a R\$ 60 milhões e, por esta razão, conforme a classificação do Bndes (2008), são consideradas "empresas de grande porte".

A indústria " $\mathrm{A}$ ", produtora de bens de consumo, possui produtos com ciclo de vida expandido e preço de mercado relativamente alto, além de vários concorrentes nos mercados em que atua. Mesmo assim, controla um número expressivo de marcas tradicionais que lhe rendem a liderança em todos os mercados onde comercializa seus produtos. A concorrência acirrada e a necessidade de evolução tecnológica geram um número expressivo de lançamentos de produtos em períodos curtos de tempo.

Já a indústria "B" enquadra-se no setor industrial de autopeças. A indústria de autopeças é caracterizada pela heterogeneidade de produtos e processos em função do número expressivo de peças e componentes utilizados em seus produtos. Produz bens de consumo com utilização indireta (o cliente final que o utiliza, não é o mesmo que o compra), ciclo de vida longo. Não possui muitos concorrentes nos mercados em que atua e é líder de vendas na maioria deles.

A indústria " $C$ " apresenta uma elevada produção anual, fato resultante da confecção de produtos de tamanhos pequenos, comercializados em grandes redes de varejo. Possui um mix de produtos amplo e uma continuidade de lançamentos elevada. A concorrência no setor ocorre em nível global, onde as mesmas marcas são comercializadas em diversos países. Mesmo assim, mantém a liderança no mercado nacional, que é atribuída ao seu sistema de logística.

Atuante em vários países, a empresa " $\mathrm{D}$ " tem suas características semelhantes à indústria "B" por possuir um elevado e heterogêneo número de peças para a produção de seus produtos, os quais possuem alto valor de mercado e um ciclo de vida consideravelmente pequeno. Devido à depreciação rápida desses produtos, pela utilização intensiva, a obsolescência é um fator que influencia o surgimento de novos produtos. Possui um elevado número de concorrentes e as inovações incrementais nos produtos são contínuas. Pela sua inserção no mercado internacional, consegue manter a liderança em alguns mercados em que atua.

As quatro empresas estudadas possuem distintos produtos e, portanto, diferentes processos de fabricação e comercialização. No entanto, todas atuam em mercados em que a concor- 
rência é extrema e a necessidade de inovação e criação de novos produtos é a chave do sucesso. No entanto, as diferenças existentes entre os negócios, com a necessidade em comum de processos eficientes para o desenvolvimento de produtos, fornecem informações relevantes que ampliam as possibilidades de desenvolvimento do framework proposto.

\subsection{Estrutura formal}

Dentre os fatores que influenciam a concepção de novos produtos, aspectos como a estrutura formal da organização é uma variável relevante que, muitas vezes, implica no fluxo de informação e tomada de decisão. Essas variáveis são apresentadas a seguir, tendo como base os dados coletados nas indústrias.

\section{a) Estrutura organizacional}

A estrutura organizacional revela como as empresas alocam os departamentos e os setores em seu organograma para a distribuição de tarefas e fases de desenvolvimento de produtos, além do grau de importância que cada indústria vê o processo de desenvolvimento de produtos.

Assim, pôde-se constatar que as indústrias possuem diferentes formas de alocação de setores de P\&D. Isto se relaciona ao fato de que, conforme a linha de produtos que comercializam, organizam suas estruturas de forma a atender a demanda de maneira simples.

Os dados coletados revelam que, na indústria " $\mathrm{A}$ ", existe a presença de dois setores voltados à geração de novos produtos. Um deles se dedica à análise e pesquisa de mercado, dos concorrentes e dos consumidores em potencial; e o outro setor preocupa-se com a prototipagem inerente ao desenvolvimento de novos produtos.

Nessa análise, também foi identificado, na indústria " $\mathrm{C}$ ", uma estrutura semelhante, ou seja, o setor de P\&D busca desenvolver o design de produto e o design gráfico a partir da leitura da concorrência e público-alvo. Nesta mesma indústria, o que chama atenção é a presença de um setor de matrizaria, que, considerando os produtos da empresa (peças cerâmicas pequenas), contribui para a confecção de protótipos e análise do processo junto ao departamento de desenvolvimento

O que se pôde notar é que as indústrias " $\mathrm{A}$ " e " $\mathrm{C}$ " desenvolvem seus produtos a partir de tendências de mercado, preocupando-se com a análise prévia de fatores estratégicos que influenciam o sucesso do produto.

Ainda com relação à estrutura organizacional, as indústrias " $B$ " e " $D$ " alocam a P\&D junto ao departamento de desenvolvimento, enfatizando, assim, as características funcionais dos produtos. Nestas indústrias, foi possível identificar um sistema sequencial de desenvolvimento, iniciado no planejamento e finalizado na etapa do processo, bem como não se preocupam com as questões de mercado e concorrência antes da idealização de seus produtos, priorizando seu desenvolvimento funcional com base em dados técnicos pré-existentes, mesmo que a sua funcionalidade não atenda às necessidades reais dos seus usuários finais.

Com relação ao departamento de $\mathrm{P} \& \mathrm{D}$, a análise revelou uma diversidade de sua alocação na estrutura organizacional. Isto parece ser intencional ao perceber que cada indústria organiza sua estrutura de desenvolvimento de produto conforme o ramo e nível de competitividade, ou seja, o objetivo final é o de oferecer a mais rápida resposta à demanda por inovação no mercado.

Em síntese, notou-se que cada indústria prioriza parâmetros estratégicos específicos conforme sua visão de mercado e nível tecnológico disponível e possível de ser adotado. Uma melhor organização dos setores seria importante para o desenvolvimento de forma sincronizada 
o cumprimento do ciclo de pesquisa, análise, criação, desenvolvimento, teste e comercialização do produto final.

\section{b) Organização do processo de desenvolvimento de produtos}

A organização dos processos de desenvolvimento de produtos mostra como ocorre o fluxo de informação dentro das indústrias, análise de mercado, demanda existente até a decisão de seu desenvolvimento, teste e comercialização.

Um ponto comum na análise entre as indústrias estudadas é relevante: o desenvolvimento de novos produtos a partir de informações externas. As empresas " $\mathrm{A}$ " e " $\mathrm{C}$ " buscam informações junto aos mercados, atingindo todas as faixas de consumidores. Já as empresas "B" e "D" levantam suas demandas junto a clientes, produzindo a partir da demanda identificada.

Nessa etapa de desenvolvimento dos produtos, os setores responsáveis pela P\&D normalmente recebem especificações já finalizadas de conceito de produto, formatando o projeto para aprovação posterior de outros setores. As decisões de comercialização e lançamento normalmente envolvem a direção da empresa.

A organização dos ciclos de desenvolvimento existente nas indústrias estudadas demonstra similaridade nos processos de transmissão da informação e tomadas de decisão. A busca de informações externas evidencia a necessidade de novas ideias, as quais culminam com a satisfação do cliente final e sucesso do novo produto.

No entanto, a tomada de decisão a respeito de conceitos e características parte de setores isolados, correndo o risco quando a análise das informações do mercado é interpretada incorreta ou limitadamente. Nessa análise, nota-se que o ideal seria que todo processo de desenvolvimento mantivesse uma equipe multisetorial que transmitisse e entregasse as informações a todos os setores envolvidos e, ao mesmo tempo, que ambos pudessem, simultaneamente, pensar e estabelecer os melhores parâmetros dentro de suas áreas de conhecimento específicas, alinhadas à maximização no processo de confecção do novo produto.

\section{c) Participação do design no desenvolvimento de produtos}

A participação do design no desenvolvimento de produtos busca demonstrar se a empresa utiliza um departamento, setor ou profissional atuante da área que atua com os conhecimentos do design no desenvolvimento de produtos. A busca tende a gerar parâmetros de inovação existentes nas empresas, já que a atividade do design de utilização de métodos de geração de alternativas que apoiam o espírito criativo motivam a inovação.

Segundo a análise dos dados coletados, as indústrias consideram o design de maneira formal, com setores inclusos em sua estrutura organizacional ou informal, com profissionais de design inseridos em outros setores de desenvolvimento de produtos.

A análise evidencia que as quatro indústrias apresentam de alguma forma o design em suas estruturas. Nas indústrias " $\mathrm{A}$ " e " $\mathrm{C}$ " existem setores específicos para a atuação do design, o que ocorre de duas formas: o design de produto e o design gráfico. A indústria " $\mathrm{D}$ ", mesmo não possuindo um setor específico descrito em sua estrutura, apresenta um profissional da área atuante dentro do departamento de engenharia. Já a empresa "B" não tem, em sua estrutura, setor ou profissionais da área, por outro lado, desempenha, na engenharia, algumas atividades que pertencem aos métodos do design de produtos.

O design pode aparecer no projeto de produtos, interferindo de maneiras diferentes na condução e no desenvolvimento do produto. Contudo, as tarefas do design aparecem nas empresas analisadas, fato este que demonstra o auxílio que o design oferece por suprir etapas essen- 
ciais para o desenvolvimento de novos produtos, levando ao entendimento de que isto se deve à facilidade para desenvolvimento de novos produtos trazidos pelo uso das técnicas de design.

\section{d) Métodos utilizados para o desenvolvimento de produtos}

Os métodos utilizados para o desenvolvimento de produtos servem para parametrizar o planejamento, criando etapas padrões a serem seguidas previamente, a fim de observar os pontos de risco e de erro, cercando os eventuais problemas que apareceriam após o projeto realizado.

As indústrias analisadas apresentam pouca incorporação de métodos em suas estruturas de planejamento e desenvolvimento. Algumas possuem instruções formais, como os casos das empresas " $\mathrm{A}$ ", "C" $\mathrm{e}$ " $\mathrm{D}$ ", utilizando métodos criados internamente. Já a empresa "B" não mostra nenhum método de concepção, assumindo uma postura operacional com relação ao departamento responsável pelo desenvolvimento de produtos.

Mesmo com procedimentos e técnicas sistematizadas, as indústrias não descrevem os reais passos que conduzem ao desenvolvimento de seus novos produtos. Nota-se a utilização de procedimentos e não métodos, ou seja, do cumprimento de etapas burocráticas que não analisam, discutem e criticam as decisões tomadas.

\subsection{Estrutura percebida}

Conforme os dados coletados nas entrevistas realizadas com os colaboradores das indústrias ligadas à $\mathrm{P} \& \mathrm{D}$ de produtos, o quadro 1 resume a operacionalização dos processos de desenvolvimento de produtos.

\begin{tabular}{|c|c|}
\hline Indústria & $\begin{array}{l}\text { A indústria dá importância à inovação, lançando em torno de } 3 \text { a } 5 \text { novos produtos ao ano como } \\
\text { meta. Porém, estas metas acabam afetando a qualidade do produto, ou seja, algumas etapas não são } \\
\text { cumpridas ou são desconsideradas em função dos prazos. A indústria mantém um banco de dados } \\
\text { que é alimentado, semanalmente, e serve de fonte de informação para a criação dos conceitos para } \\
\text { novos produtos. }\end{array}$ \\
\hline Indústria & $\begin{array}{l}\text { A indústria enfatiza a funcionalidade e versatilidade de seus produtos, sendo a importância mecânica } \\
\text { tomada como prioritária. Questões relacionadas à ergonomia e à adaptação dos componentes aos } \\
\text { mercados específicos são colocadas em segundo plano, assim como padrões estéticos. A empresa } \\
\text { lança produtos de acordo com a demanda do mercado, assumindo uma postura de agregação ou } \\
\text { melhoria aos já existentes. }\end{array}$ \\
\hline Indústria & $\begin{array}{l}\text { A indústria trabalha com o lançamento contínuo de produtos que são desenvolvidos para nichos de } \\
\text { mercados. O desenvolvimento contínuo também ocorre com estudos de novas matérias -primas } \\
\text { utilizadas na produção de produtos }\end{array}$ \\
\hline Indústria & $\begin{array}{l}\text { A indústria realiza lançamentos de acordo com pedidos dos clientes, o que gera muitos projetos } \\
\text { específicos e uma variedade no mercado, sem oferecer, muitas vezes, inovações significativas. Alguns } \\
\text { produtos específicos são analisados e estudados de maneira mais profunda, diminuindo o número de } \\
\text { retrabalhos após seu lançamento. }\end{array}$ \\
\hline
\end{tabular}

Quadro 3 - Participação do design no desenvolvimento de produtos.

Fonte: Dados da pesquisa (2008).

Os dados coletados e organizados no quadro 1 apresentam o processo de desenvolvimento de produtos nas indústrias estudadas. Observam-se alguns pontos de divergentes com relação a esta análise, em especial, a falta de comunicação interna e falha na entrega das informações. Um exemplo disso é o fato de nenhuma resposta dos entrevistados citou quaisquer métodos de concepção de produtos, apesar de enfatizarem o cumprimento dos prazos de lançamento para novos produtos. 
As análises dos dados apresentam diferenças entre estruturas demonstradas estrategicamente e o real desenvolvimento operacional existente. Isto mostra que o planejamento estratégico para o desenvolvimento de produtos apresenta etapas não citadas nos relatos dos colaboradores atuantes nas áreas de projeto e desenvolvimento operacional de produtos. $\mathrm{O}$ tratamento do desenvolvimento de produtos e as distâncias, principalmente de comunicação existentes entre os atos "estratégicos" e "operacionais", ainda são barreiras que devem ser quebradas, a fim de que os verdadeiros propósitos da indústria sejam alcançados eficientemente.

\subsection{Considerações acerca do processo de concepção de produtos}

Conforme a análise dos dados, verificou-se que as indústrias não possuem concepções metodológicas para o desenvolvimento de produtos, possuindo apenas algumas ferramentas que auxiliam em determinadas variáveis que são de maior ou menor importância.

As indústrias " $\mathrm{A}$ " e " $\mathrm{C}$ " utilizam uma estrutura corporativa que tem um ambiente mais propício para o desenvolvimento de produtos, orientando suas concepções para o mercado, onde o design é visto como parte da estratégia da indústria. Tal fato pode ser visto nas suas estruturas organizacionais que trazem o design dentro de outros setores.

Já as indústrias "B" e "D", por sua vez, têm uma estrutura de departamentos, onde a P\&D está situada no departamento de engenharia, sem poder de decisão e as alterações podem ser feitas apenas após uma consulta à direção. Nesta estrutura organizacional, poucos conhecem a estratégia da indústria e os responsáveis pelo desenvolvimento de produtos atuam como peças operacionais, sem análise crítica ou ligação sistêmica com os demais setores.

Nesse aspecto, a descrição de organogramas são ferramentas que explicam o posicionamento do design dentro da organização. A empresa " $\mathrm{A}$ " se enquadra no conceito venture, dando total liberdade aos projetos de design, bem como a indústria " $\mathrm{C}$ ". Já as indústrias " $\mathrm{B}$ " $\mathrm{e}$ " $\mathrm{D}$ " enquadram o design como uma função independente, uma vez que o design (engenharia) costuma ser visto pela diretoria como atividade que apenas gera despesas.

Percebe-se também que as atuais metodologias aplicadas ao produto são operacionais, colocando o design somente como uma tarefa dentro do departamento, ou seja, para que uma empresa tenha sucesso no lançamento de produtos, o design deve ser estratégico. Nas indústrias pesquisadas, observou-se que a formação dos profissionais envolvidos na área do design demonstra características predominantemente operacionais.

Dessa forma, podem-se dividir as análises interpretando que as indústrias " $\mathrm{A}$ " e " $\mathrm{C}$ " definem o design como um processo inovador, em que o profissional deve ter conhecimento de gestão organizacional, estar atualizado e sensível ao comportamento do mercado. Além disto, deve possuir uma visão sistêmica, mas com conhecimento regional, trabalhando de uma forma multidisciplinar, ou seja, ser um departamento que, entendendo de estratégias de mercado, trabalhe em harmonia com outros departamentos e profissionais. Por outro lado, as indústrias " $\mathrm{B}$ " e " $\mathrm{D}$ " entendem que o departamento de design deve possuir conhecimentos de ergonomia, ser capaz de trabalhar o aspecto formal e atender à questão operacional da área.

\subsection{Framework proposto: a gestão de design}

As organizações estão sempre em busca de ferramentas que promovam sua competitividade, assim como modelos de gestão para sobrevivência e manutenção no mercado. Diante disso, o framework de gestão proposto aprimora e combina conceitos, constituindo-se de uma inovação em relação à estratégia. 


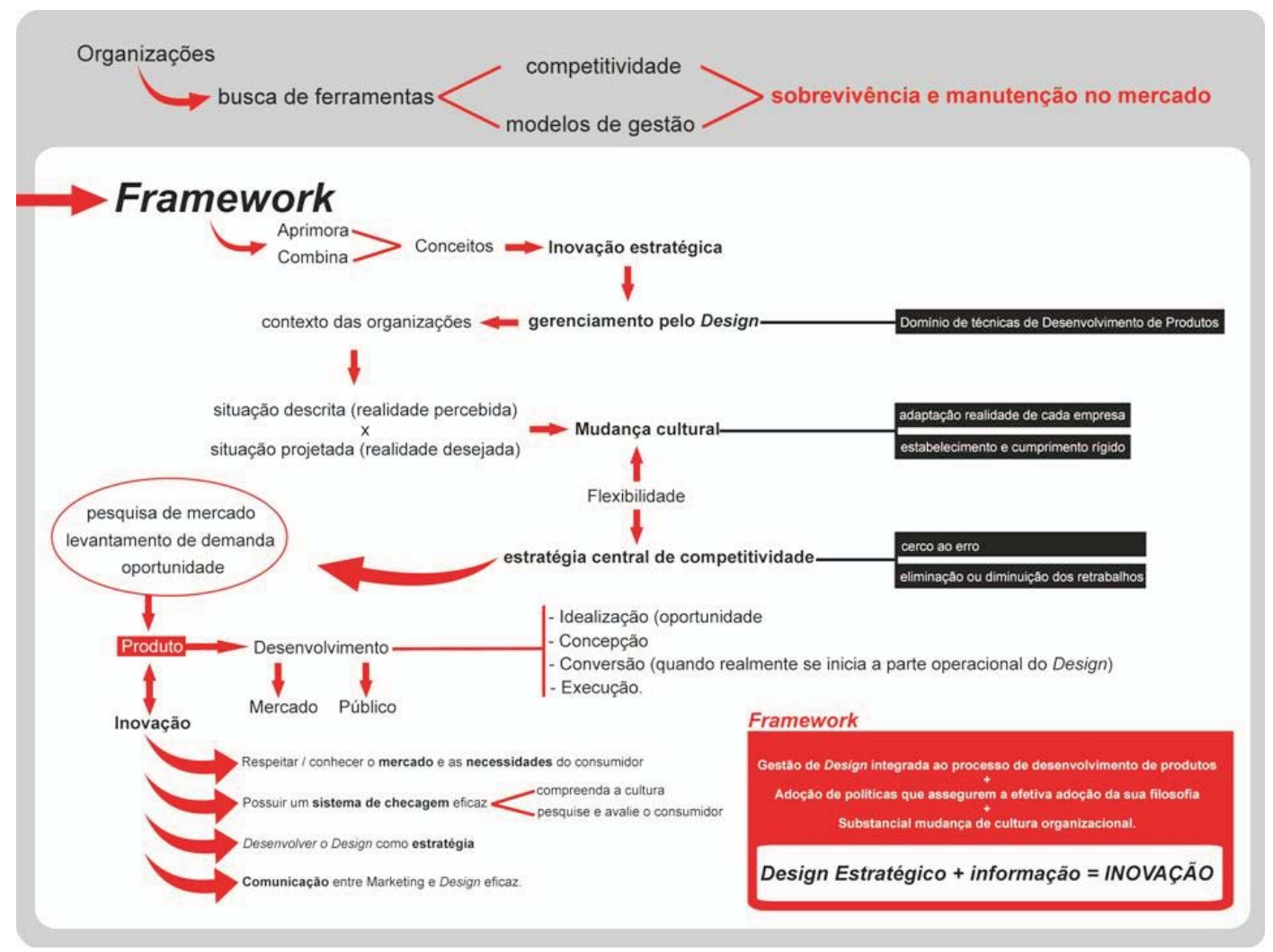

Figura 1 - Framework de gestão de design.

Fonte: elaborada pelos autores.

O framework é uma proposta de gestão de design em organizações e que deve ser adequado ao contexto e aplicado e de acordo com a estratégia central que possui um objetivo duplo: tornar gerentes e designers parceiros e definir os métodos de gestão para integrá-lo na organização.

O framework apresentado na figura 1 destaca a gestão de design como força estratégica, atuando principalmente na pesquisa de mercado e levantamento de demandas ou de oportunidades. O produto só poderá ter seu sucesso garantido se possuir seu desenvolvimento específico para o mercado e público para o qual foi desenvolvido. A gestão de design, como estratégia, visa também a delimitar o que realmente o mercado busca ou em que realmente é preciso inovar para se alcançar espaço neste mercado.

Pode-se estabelecer quatro etapas que devem ser observadas, independentemente do produto a ser lançado e aplicação de acordo com as necessidades e possibilidades da empresa em que será implementado, a saber: (a) idealização (oportunidade); (b) concepção; (c) conversão (quando realmente se inicia a parte operacional do design); e, (d) execução. Essas etapas, adaptadas à cultura e realidade de cada empresa, se estabelecidas e cumpridas com rigidez, cercam o erro e eliminam ou diminuem em sua totalidade os retrabalhos.

Para o cumprimento operacional, a gestão de design deve ter o domínio de um conjunto de técnicas de desenvolvimento de produtos, considerando-se como indispensáveis as seguintes etapas: (a) os métodos associativos: técnicas que encorajam reações espontâneas, associando o conceito do novo produto a elementos e mecanismos; (b) os métodos de confrontação criativa: são métodos, caracterizados pela associação de ideias já existentes; e (c) os métodos de análise sistemática: baseados na sistemática descrição do problema. 
Para a orientação estratégica e operacional, a gestão de design deve respeitar e conhecer o mercado e as necessidades do consumidor, possuindo um sistema de checagem dinâmico que compreenda a cultura, pesquise e avalie o consumidor. No entanto, observa-se que, para que um produto seja orientado ao consumidor, deve haver uma boa comunicação entre as funções de marketing e design, uma vez que esta etapa é de suma importância para o sucesso do produto no mercado e, para que isto aconteça, o design deve ser estratégico e a comunicação entre marketing e design deve ser eficaz.

Assim, a proposta de gestão de design pode ser vista como um sistema focado na maximização do fluxo de informações, no desenvolvimento de novos produtos, sendo o design uma ferramenta estratégica de inovação nas organizações.

\section{CONSIDERAÇÕES FINAIS}

Este trabalho teve como objetivo o desenvolvimento de um framework de gestão de design focado na maximização do fluxo de informações no desenvolvimento de produtos inovadores em organizações competitivas.

A bibliografia que trata do tema relata que produtos caros, sofisticados e mais complexos são considerados de maior qualidade que produtos similares mais simples. A qualidade, na visão popular, pode ser discutida, sentida e julgada, mas não pode ser medida, controlada, nem gerenciada. Na visão do profissional do design, aspectos relacionados com os requisitos designados para o produto devem ser medidos, definidos, monitorados, gerenciados e melhorados.

As empresas estão percebendo que a dinâmica nos negócios inovadores são afetados cada vez mais pela competição. As empresas veem o design como aliado de produtos, serviços e processos inovadores, como um meio de alcançar uma vantagem competitiva sustentável.

A análise percebida de como o desenvolvimento de produtos ocorre em contraponto às estruturas formais contidas nas empresas, demonstra que ainda ocorrem distorções no processo. O desafio de fazer com que a gestão de design seja integrada, neste caso ao processo de desenvolvimento de produto, requer a adoção de políticas e práticas que demandam comprometimento e persistência por parte dos gestores tomadores de decisão. Neste contexto, a maior dificuldade para se difundir a gestão de design parece estar na necessidade de assegurar a efetiva adoção da sua filosofia, o que implica numa substancial mudança de cultura organizacional que é alcançada, na maioria das vezes, no longo prazo.

Diante das considerações apresentadas, pode-se dizer que a pesquisa junto ao mercado, o planejamento, a integração, o controle de qualidade, juntamente com a informação adequadamente disseminada, são alguns dos principais elementos a serem observados para o sucesso de concepção e de desenvolvimento de novos produtos.

\section{REFERÊNCIAS BIBLIOGRÁFICAS}

AVENDAÑ̃, L. E. Gestão do design. Disponível em: <http://www.dezine.com.br/zine/003/ avendano_003.htm>. Acesso em: 12 dez. 2007.

BAXTER, M. Projeto de produto: guia prático para o design de novos produtos. 2. ed. São Paulo: Edgard Blucher, 1998.
BITTENCOURT, A. C. P. Desenvolvimento de uma metodologia de reprojeto de produto para o meio ambiente. 2001. 198f. Dissertação (Mestrado em Engenharia Mecânica)-Programa de Pós-Graduação em Engenharia Mecânica, Universidade Federal de Santa Catarina, Florianópolis, 2001. 
BOMFIM, G. A. Metodologia para o desenvolvimento de projeto. João Pessoa: Universidade Federal da Paraíba, 1995.

BONSIEPE, G. Metodologia experimental/desenho lindustrial. Brasília: CNPq/ Coordenação Editorial, 1984.

COUTINHO, L. G.; FERRAZ, J. C. Estudo da competitividade da indústria brasileira. Campinas: Universidade Estadual de Campinas, 1995.

D'AJUZ, M. C. L. Modelo de gestão: diferencial de competitividade ou uma grande incógnita? Disponível em: <http://www.perspectivas.com.br/ art71.htm >. Acesso em: 03 nov. 2007.

DRUCKER, P. Sociedade pós-capitalista. São Paulo: Pioneira, 1995.

FASCIONI, L. O que é mesmo design? Disponível em: <http://www.acontecendoaqui.com.br/ co_fascioni02.php>. Acesso em: 07 nov. 2007.

FERREIRA, A. B. H. Novo dicionário Aurélio da língua portuguesa. 3. ed. Curitiba: Positivo, 2004.

FERREL, O. C. Estratégias de marketing. São Paulo: Atlas, 2000.

HAUSER, Jr.; GRIFFIN A. Patterns of communication among marketing, engineering and manufacturing: a comparison between two new product team. Management Science, v.38, p. 360-373, 1992.

KISTMANN, V. B. Tendências estratégicas e design: o consumidor como nova competência. Estudos em Design, Rio de Janeiro, v. 9, n. 3, p. 28-36, out. 2002.

KOTLER, P. Administração de marketing. São Paulo: Atlas, 1996.

KOTLER, P. Administração de marketing. São Paulo: Prentice Hall, 2000.

KOTLER, P.; ARMSTRONG, G. Princípios de marketing. São Paulo: LTC, 1999.
LÖBACH, B. Desenho industrial: base para configuração dos produtos industriais. São Paulo: Edgar Blucher, 2000.

MAGALHÃES, C. Design estratégico: integração e ação do design industrial. Estudos em Design, v. 3, n. 1, p.15-27, jul. 1997.

MONTEIRO, E. A Gestão estratégica nas empresas. Grupo Gestão Deloitte, 2003.

MOZOTA, B. B. Structuring strategic design management. Design Management Journal, p.2631, spring, 1998.

SEMENIK, R., BAMOSSY, G. J. Princípios de marketing: São Paulo: Makron, 1996.

SOARES, V. F. Escola de Belas Artes. Curso de Desenho Industrial. Rio de Janeiro. Disponível em: < http://www.eba.ufrj.br/aula/gp/> Acesso em: 06 dez. 2007.

STONER, J. A. F., FREEMAN, R. E. Administração. Rio de Janeiro: Prentice-Hall, 1985.

TRIVIÑOS, A. N. S. Introdução à pesquisa em ciências sociais: a pesquisa qualitativa em educação. São Paulo: Atlas, 1992.

TRUEMAN, M. Managing innovation by design: how a new design typology may facilitate the product development process in industrial companies and provide a competitive advantage. European Journal of Innovation Management, v.1, n.1, p.44-56, 1998.

VERGARA, S. Projetos e relatórios de pesquisa em administração. São Paulo: Atlas, 1997.

WOLF, B. O design management como fator de sucesso comercial. Florianópolis. FIESC/IEL, ABIPTI, Programa Catarinense de Design, SEBRAE, CNPq, 1998.

YIN, R. K. Estudo de caso: planejamento e métodos. 2. ed. Porto Alegre: Bookman, 2001. 